\section{$\mathrm{NHH}$ promises funds to help biologists to use beamlines}

[WASHINGTON] The US National Institutes of Health (NIH) is set to provide a major infusion of equipment and technical staff to help biologists working at five synchrotron light sources operated by the Department of Energy (DOE).

Harold Varmus, director of the NIH, told a meeting last week of health research lobbyists: "We'll be making a substantial contribution" to the synchrotron facilities "in the future, and perhaps this year".

The NIH contribution may be as much as $\$ 20$ million in the current financial year, which ends in September 1999. It is expected to help equip beamlines at the synchrotrons, to upgrade some of the facilities, and to pay for support staff to help structural biologists use them.

It has been estimated that a capital investment of $\$ 12$ million and an extra $\$ 5.5$ million in annual operating costs would double the amount of time available on the beamline for structural biologists at the synchrotrons (see Nature 393, 3; 1998).

The increased NIH contribution confirms that the biomedical research agency, which last month received a mammoth \$2 billion funding increase from the Congress, is ready to help the cash-strapped DOE with facility operations.

The DOE built most of the 'big science' instruments in the United States, including the synchrotrons, chiefly for use by physicists and materials scientists. But an increasing proportion of their users are NIH-supported biologists.

A panel of officials established in the spring to look into the question of interagency cooperation on synchrotron operations recently sent its report to the Office of Science and Technology Policy at the White House. The agencies involved are now trying to implement its findings during the current financial year.

Marvin Cassman, director of the National Institute of General Medical Sciences at NIH, says: "I do anticipate we'll be making a substantial contribution". But he adds that its precise value remains "a little unclear" and that he is "still not certain we can do it this year". NIH is currently scrambling to allocate its unexpectedly large budget increase.

The facilities that will benefit from the news include the Advanced Photon Source at the Argonne National Laboratory, Illinois; the Advanced Light Source at the Lawrence Berkeley laboratory in California; the Stanford Synchrotron Radiation Laboratory at Stanford, also in California; and the National Science Foundation's synchrotron at Cornell University, New York State. Colin Macilwain

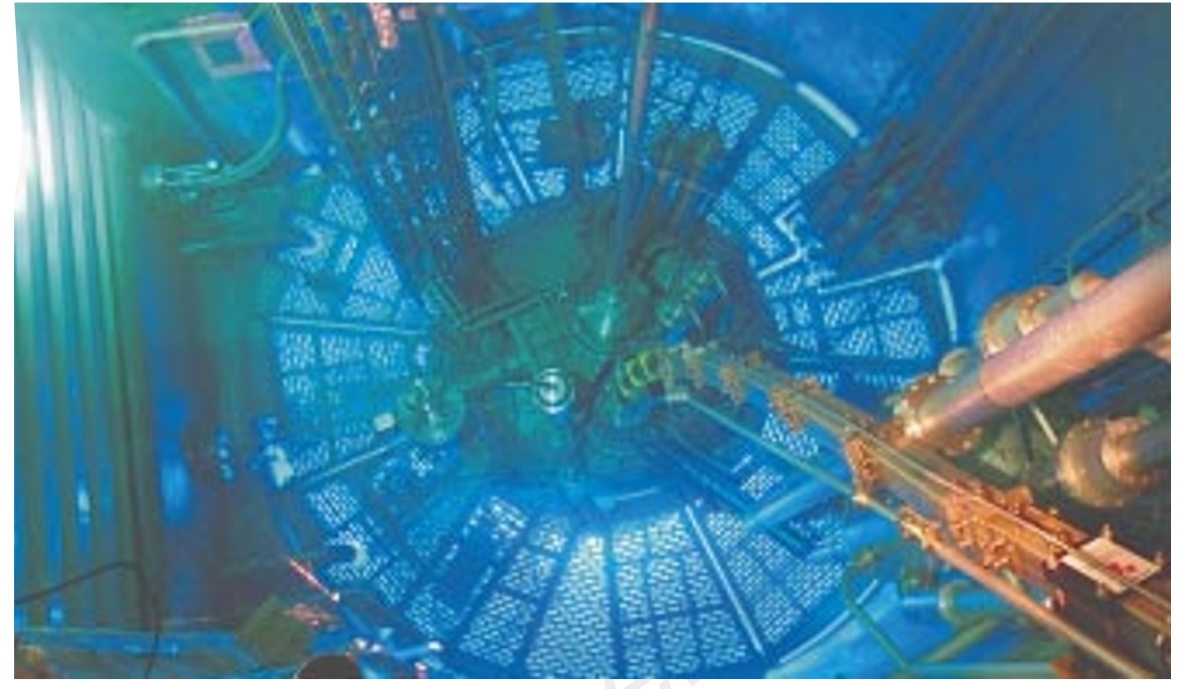

Deep blue: light is emitted from the core of the ILL reactor as a result of Cerenkov radiation.

\title{
European reactor accepts US demands on fuel shift
}

[MUNICH] The Institut Laue Langevin (ILL) in Grenoble, France, has bowed to US pressure and agreed to convert its high-flux 57 MW research reactor to use low enriched uranium (LEU) rather than 'bomb-grade' highly enriched uranium (HEU). The move follows the institute's failure to secure sources of HEU from Russia.

According to a memorandum of understanding signed on 12 November, the conversion will take place "when it becomes technically and economically possible". In return, the United States will supply HEU to the reactor until it converts, and also take back spent fuel.

The Reduced Enrichment for Research and Test Reactors (RERTR) programme, which started in 1978, requires the United States to promote the development of LEU fuel for reactors wishing to convert. The programme is intended to reduce international commerce in bomb-grade uranium.

It was strengthened in 1992 by the socalled Schumer Amendment, banning the delivery of US HEU to reactors that refuse to cooperate with the RERTR programme. The amendment was named after Democrat Congressman Charles Schumer, who earlier this month defeated incumbent Alfonse D'Amato to win a seat in the US Senate, representing New York.

As a result of US pressure, most research reactors have converted to existing LEU fuel or have agreed to work with US scientists to develop LEU fuel which they can use without loss of performance or extra cost. The ILL reactor, which provides neutron beams for structural analysis for scientists from ILL's seven member states, was one of the few to hold out, partly because France objected to US interference in European affairs.
When the ILL restarted operation in 1995 after a four-year shutdown for repair, it found its normal fuel supply blocked by the Schumer agreement. ILL officials turned to Russia for HEU supplies rather than accept US terms, and Russia became an associate member of ILL in November 1996 in exchange for supplying HEU from Minatom, the Russian Atomic Agency.

But the Russian fuel failed to materialize and ILL suspended Russian membership at the beginning of this year. Dirk Dubbers, the director of the ILL, cites "problems between the Russian science ministry, which benefited from the scientific opportunities, and Minatom, which saw no exchange of cash".

The agreement between ILL and the United States took observers by surprise. A spokesman for Greenpeace International described it as "welcome, even if not motivated by non-proliferation concerns".

The European Union's Petten research reactor in Belgium and Belgium's national research reactor BR2 have long expressed interest in conversion, but have not yet agreed to do so. If they do convert, the only remaining European reactor to hold out will be the controversial German research reactor FRM II, being built by the Technical University of Munich.

The operators of FRM II have cited the reluctance of ILL to comply with US terms for HEU supply as support for their reluctance to do so. But the ILL's change of heart comes on top of a statement from the new red-green federal government in Germany saying that use of bomb-grade uranium in research reactors is "problematic and dubious in terms of foreign policy". The statement says the government will check again whether FRM II could be converted to LEU.

Alison Abbott 